\title{
Aging Effects on Anatomy and Neurophysiology of Taste and Smell ${ }^{1}$
}

\author{
Charlotte M. Mistretta, Ph.D.²
}

\begin{abstract}
Taste and smell have a primary role in food ingestion. Therefore, to understand why eating habits alter in elderly people, age-related differences in the chemical senses should be investigated. In early anatomical studies, substantial decreases in numbers of taste buds in old human and mouse circumvallate papillae were observed. However, recent investigations in humans, monkeys, and rats indicate that there is not a significant loss of taste buds in old age. Neurophysiological recordings from the chorda tympani nerve, innervating taste buds in fungiform papillae, demonstrate significant but small differences in response magnitudes for some chemicals in old rats. Greater age-related differences have been observed in the olfactory sense. Numbers of receptor neurons in the rat olfactory epithelium initially increase in adults and then decline in old animals; this decline is reflected in subsequent changes in the olfactory bulb. However, numbers of synapses in the bulb per receptor neuron are increased in the oldest rats, suggesting some compensatory mechanism. Differences in degree of aging effects in taste and smell might relate to the nature of receptors: a modified epithelial cell in taste versus a neuron in smell. However, in both sensory systems, large numbers of receptors remain even in old age. Since taste bud cells and olfactory receptors turn over and are replaced throughout life, the peripheral taste and smell systems might be relatively resistant to aging effects.
\end{abstract}

Important in the perception of flavor are not only the taste and smell of food, but also the temperature and tactile qualities, and the visual presentation of a meal. However, of these various sensory systems, taste and smell have a primary role in detection, identification, and acceptance or rejection of the various chemical stimuli in food. The chemical senses are essential both for appropriate nutrient selection and for deriving pleasure from eating. Therefore, to understand why eating habits and sensory responses to food alter in elderly people, it is necessary to examine age-related differences in the chemical senses, taste and smell. In this paper, data on anatomical and neurophysiological characteristics of the chemical senses in old age will be discussed.

\section{TASTE}

\section{Anatomy of the Taste System in Old Age}

Humans. The gustatory system is unique in that the receptors are widely distributed throughout the oropharynx and the peripheral innervation is via branches of three different cranial nerves [Bradley, 1981]. The chorda tympani branch of cranial nerve VII (facial) innervates taste buds in fungiform papillae on the anterior tongue and in the anterior-most ridges of the foliate papillae. The greater superficial petrosal nerve branch of VII innervates taste buds on the soft palate. Taste buds in the circumvallate papillae and posterior ridges of the foliate papillae are innervated by the lingual branch of cranial nerve IX, the glossopharyngeal. Finally, taste buds on the epiglottis are innervated by the superior laryngeal nerve branch of cranial nerve $X$, the vagus. Therefore, due to the difference in innervation, studies of taste buds in any one region of the oropharynx cannot generalize necessarily to all taste buds.

In anatomical studies of the taste system in old age, light microscopic techniques have been used to examine the question of whether or not taste buds are decreased in number in elderly individuals. In the 1930s two laboratories independently investigated taste buds on the back of the tongue in humans. Buds were counted in seriallysectioned circumvallate papillae dissected from cadaver tongues, aged birth to greater than 90 years [Arey, et al., 1935; Mochizuki, 1937]. It was reported that in the oldest individuals, aged about 75-90 years, numbers of taste buds were reduced by more than $50 \%$ compared to numbers in younger individuals (Figure 1).

On the other hand, as presented in Figure 1, taste buds in foliate papillae from human cadaver tongues were observed to increase in number from juvenile $(0-20$ years) to mature (21-73 years) ages, and then decrease again in old age (74-90 years) to numbers that equalled those in the juvenile group [Mochizuki, 1939].

The changes in taste bud numbers as a function of age in humans that were reported in the early literature are

\footnotetext{
'Address reprint requests to Dr. Charlotte M. Mistretta, Department of Oral Biology, School of Dentistry, University of Michigan, Ann Arbor, MI 48109, U.S.A. Preparation of this manuscript was supported by National Science Foundation Grant BNS $83-11497$ and N.I.D.R., N.I.H. Grant DE 05728 .
}

${ }^{2}$ From the Department of Oral Biology, School of Dentistry, Center for Human Growth and Development, and Center for Nursing Research, School of Nursing, University of Michigan, Ann Arbor, Michigan 48109, U.S.A

\$1984 Beech Hill Enterprises, Inc. 


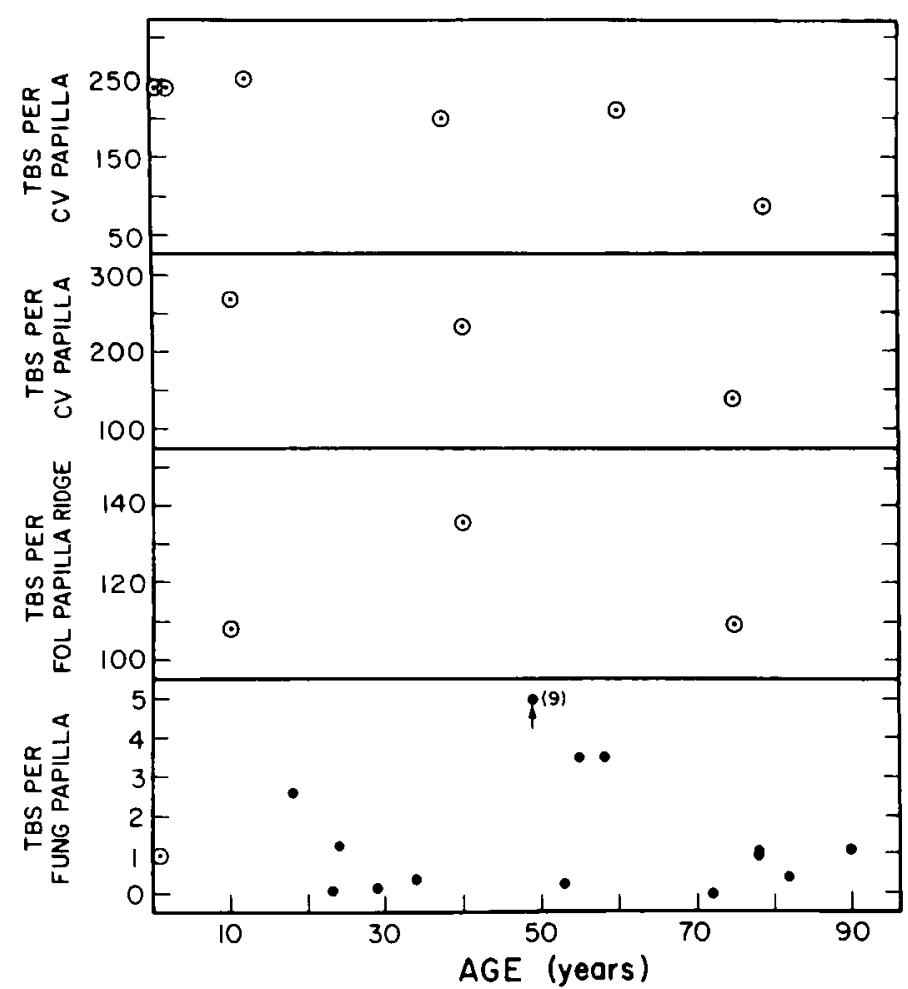

Figure 1. Summary of results on numbers of taste buds in human papillae as a function of age. Data in panel one are on circumvallate papilla, from Arey, et al. [1935]; in panel two are data on circumvallate papilla from Mochizuki [1937]; in panel three are data on foliate papilla from Mochizuki [1939]; in panel four are data on fungiform papilla from Arvidson [1979]. All data points (open circles with dots) are means for age groups, with the exception of those on fungiform papillae (closed circles) which are mean data from several papillae in one individual. Note that scales on the ordinate are different for each panel. The studies of taste bud numbers in circumvallate papillae demonstrated a decrease in old age. Taste buds in foliate papillae reportedly increased and then decreased. Numbers of taste buds in fungiform papillae did not differ as a function of age.

in contrast to a more recent study of taste buds in fungiform papillae on the anterior tongue [Arvidson, 1979]. Fungiform papillae were dissected from cadaver tongues, aged 2 days to 90 years, and serially-sectioned. There was no significant correlation between numbers of taste buds per papilla and the age of the individual (Figure $1)$.

It is noteworthy that a reduction in density of fungiform papillae (number of papillae per unit area of tongue) was reported on the human tongue from 4-55 years of age [Moses, et al., 1967]. This decrease in density of papillae would be expected to accompany growth of the tongue. The tongue approximately doubles in area from 4-18 years, and growth continues beyond 18 years [Cohen \& Vig, 1976]. The study on papilla density does not extend data into old age, nor does it relate to taste bud or papilla number but rather to papilla distribution on the tongue. Therefore it should not be confused with studies directly investigating numbers of taste buds in young and old individuals.

The publications on taste bud numbers in various papillae on the human tongue leave a somewhat confus- ing picture. Taste buds reportedly decrease in circumvallate papillae as a function of age [Arey,et al., 1935; Mochizuki, 1937],increase and then decrease to juvenile levels in foliate papillae [Mochizuki, 1939], and remain the same in fungiform papillae [Arvidson, 1979]. The differences between those investigations in the earlier literature on circumvallate and foliate papillae [Arey, et al., 1935; Mochizuki, 1937; 1939] and recent studies on fungiform papillae [Arvidson, 1979] relate not only to examination of different papilla types, but also to variations in methods and data analysis. Only Arvidson [1979] included a statistical analysis of the data. Since variability can be high in results of age-related differences, statistics are essential. In addition, only in the recent work [Arvidson, 1979] were tissue samples limited to fresh cadavers (within 5 to 12 hours after death by traffic accident or sudden cardiac infarction). Cases where medical records indicated any pathology of the oral cavity, pharynx, face or neck were excluded. Arey and colleagues [1935] stated that they avoided study of highly pathological specimens and only included well-preserved tongues. Mochizuki [1937] stated that he studied 'fresh' tongues. No information was provided in these early investigations on medical histories of individuals in the sample.

Animals. Problems related to tissue preservation and control for possible pathology can be addressed readily with non-human species. As in human studies, only light microscopic techniques have been applied to study of the taste system and the question addressed has remained rather superficial: are taste buds lost in old age? For example, recently in the author's laboratory, taste buds were counted in fungiform, circumvallate and foliate papillae from tongues of 15 rhesus monkeys in 5 groups aged 4-31 years [Bradley, et al., 1984]. To count buds in fungiform papillae, the tongue was stained with a surface application of Ponceau S [Brouwer \& Wiersma, 1978] and the taste pores were then counted. Accuracy of the method was verified by histological examination of taste buds in ten papillae from each tongue. For circumvallate counts, the two or three most centrally located papillae were dissected, serially-sectioned, and all taste buds were counted. Finally, all ridges of one foliate papilla were serially-sectioned and all taste buds counted.

There was no significant difference in numbers of taste buds as a function of age in any of the lingual papilla types (Table 1). In fungiform papillae, numbers of taste buds ranged from $0-31$, similar to the range of $0-27$ reported for human fungiform papillae [Arvidson, 1979]. The average number of taste buds varied from 4-5 per papilla across all age groups. Average numbers of taste buds per circumvallate papilla varied from $572-827$ across ages. Averages per foliate papilla (including all ridges within the entire papilla) were from 1777-2823. Since there were no differences in average taste bud numbers as a function of age for any papilla type, the proportions of taste buds represented in fungiform, foliate or circumvallate papillae also did not change.

There are other age-related studies of taste bud numbers, in old rodent tongues. Taste buds were counted in the single circumvallate papilla of mice aged 6 through 
Table 1

Average Numbers of Taste Buds in Fungiform, Circumvallate and Foliate Papillae of the Rhesus Monkey as a Function of Age.*

\begin{tabular}{|c|c|c|c|c|c|}
\hline \multirow{2}{*}{$\begin{array}{l}\text { Average Number } \\
\text { of Taste Buds } \\
\text { Per Papilla }\end{array}$} & \multicolumn{5}{|c|}{ Age (Years) } \\
\hline & 4 & 8 & 13 & 24 & 31 \\
\hline $\begin{array}{l}\text { Fungiform } \\
\qquad(S D)\end{array}$ & $\begin{array}{c}4.2 \\
(0.1)\end{array}$ & $\begin{array}{c}5.3 \\
(1.3)\end{array}$ & $\begin{array}{c}4.8 \\
(0.6)\end{array}$ & $\begin{array}{c}3.9 \\
(0.4)\end{array}$ & $\begin{array}{c}4.7 \\
(0.6)\end{array}$ \\
\hline $\begin{array}{l}\text { Circumvallate } \\
\qquad(S D)\end{array}$ & $\begin{array}{l}592 \\
(72)\end{array}$ & $\begin{array}{c}823 \\
(329)\end{array}$ & $\begin{array}{l}646 \\
(77)\end{array}$ & $\begin{array}{c}827 \\
(196)\end{array}$ & $\begin{array}{c}572 \\
(182)\end{array}$ \\
\hline $\begin{array}{r}\text { Foliate } \\
(S D)\end{array}$ & $\begin{array}{c}2334 \\
(1003)\end{array}$ & $\begin{array}{c}2823 \\
(1159)\end{array}$ & $\begin{array}{l}1822 \\
(588)\end{array}$ & $\begin{array}{l}1992 \\
(254)\end{array}$ & $\begin{array}{l}1777 \\
(526)\end{array}$ \\
\hline
\end{tabular}

* Standard deviations $(S D)$ are in parentheses. Three animals were studied in each age group. Values for foliate papillae are for the entire papilla, including all ridges. Data are from Bradley, et al., [1984].

27 months [Conger \& Wells, 1969]. A progressive linear decline in number of buds was observed across the life span, and by 27 months taste buds were reduced in number by about $25 \%$ relative to mice aged 6 months. However, statistics were not applied for data analysis in this study nor were taste buds counted in all sections of the circumvallate papilla.

More recently, taste buds have been examined and counted in all serial sections of the circumvallate papilla from Wistar-derived rats in two age groups, 6 months and 24 months [Mistretta \& Baum, 1984]. The mean life span of these rats is about 24 months. Average numbers of taste buds in the circumvallate papilla were 460 at 6 months and 473 at 24 months; there was no significant difference between taste bud numbers for the two age groups. Furthermore, the fungiform papillae from these rat tongues were sectioned to determine whether each papilla contained the single taste bud characteristic of rat fungiform. In rats aged 6 months, $99 \%$ of all papillae that were examined contained one taste bud each and at 24 months $98 \%$ contained one taste bud.

In our laboratory, we are completing studies of taste buds in fungiform papillae of Fischer 344 rats aged 4-37 months. These rats, obtained through the National Institute on Aging, were barrier-bred and maintained to reduce possibility of infection. Even in rats aged 30 months and older, at least $90 \%$ of all papillae examined contained a taste bud. Our data indicate that there is no substantial age-related loss of taste buds in fungiform papillae in this strain, supporting results from the Wistarderived rats [Mistretta \& Baum, 1984].

\section{Neurophysiology of the Taste System in Old Age}

Although the most recent studies indicate that there is not a large age-related loss of taste buds, there may be alterations in cell receptor membranes in the taste buds of aged animals. Cells of the taste bud turn over and are replaced every ten days [Beidler \& Smallman, 1965]. This cell replacement must continue in old age because if it ceased completely, degenerating taste cells would not be replaced and eventually no taste buds would remain. However, if turnover time is slower in aged animals, the taste receptor membranes could age as the cells survive beyond their usual life span [Mistretta, 1984].
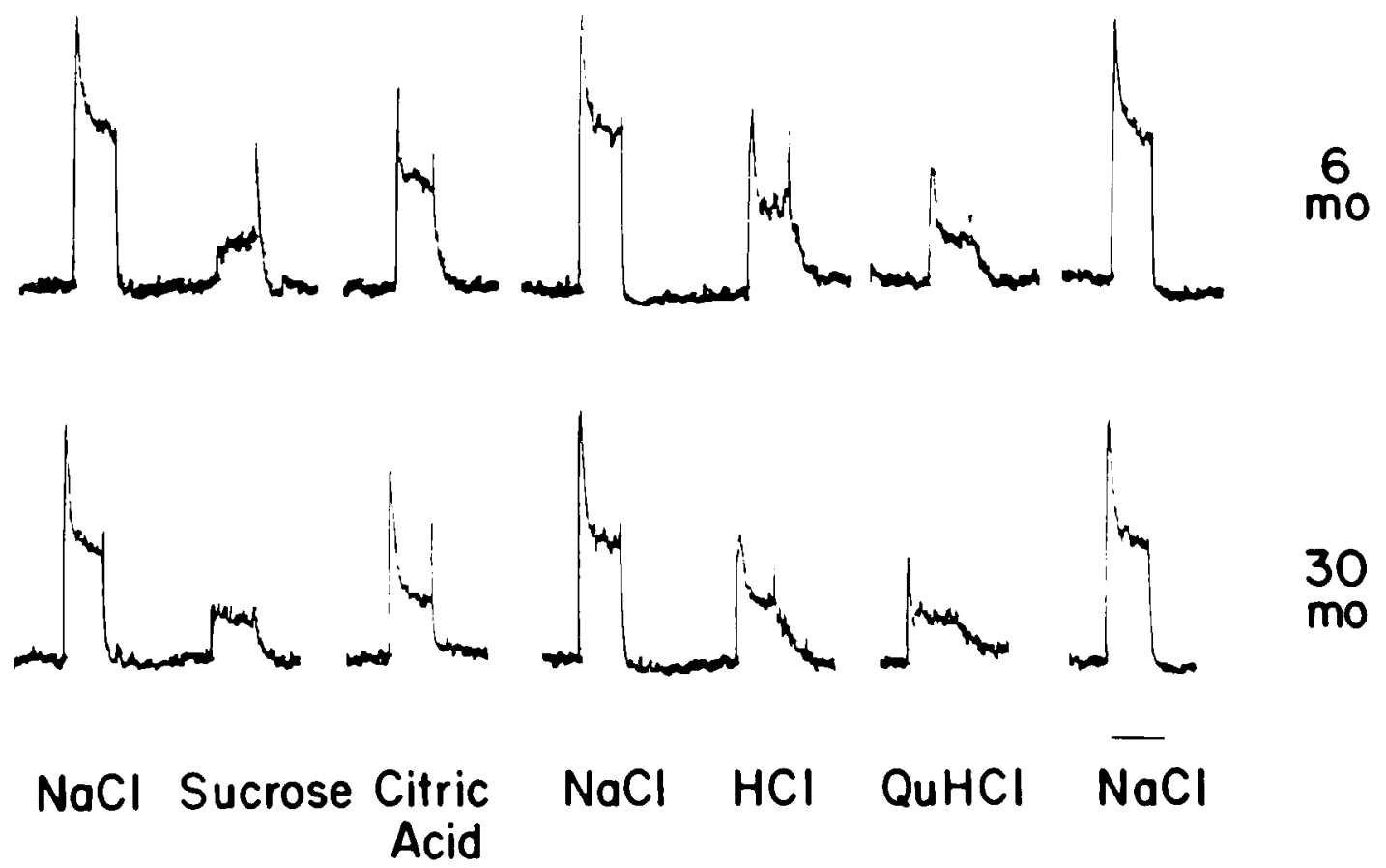

Figure 2. Summated recordings of neurophysiological responses from the chorda tympani nerve to various chemical stimuli on the anterior tongue. Data are from two Fischer 344 rats, aged 6 and 30 months respectively. The recordings are continuous but have been interrupted at very long rinse periods ( 2 to 3 minutes). The black time bar at the bottom of the figure represents 30 seconds. Even in 30 month rats, substantial chorda tympani nerve responses to various chemical stimuli were obtained. 
Age-related changes in receptor cell membranes presumably would be reflected in altered electrophysiological responses from peripheral taste nerves. Responses have been recorded from the chorda tympani nerve, which innervates taste buds on the anterior tongue, in three age groups of Fischer 344 rats: 6, 24 and 30 months [McBride, 1983; McBride \& Mistretta, 1983]. Median life span in these animals is about 26 months. Even in the oldest rats, large responses were obtained from the whole nerve during lingual stimulation with salts, acids, sucrose and quinine hydrochloride (Figure 2). Therefore the taste system maintains the ability to respond to a variety of chemicals with substantial response magnitudes.

However, there are some statistically significant changes in relative response magnitudes. For example, when compared to $\mathrm{NaCl}$, responses to $\mathrm{NH}_{4} \mathrm{Cl}$ and sucrose increase as a function of age, and responses to $\mathrm{MgCl}_{2}$ and citric acid decrease. Responses to $\mathrm{NaCl}$ itself change, as demonstrated by study of responses to $\mathrm{NaCl}$ over a wide range of concentrations. In the oldest rats, responses to high concentrations $(>0.25 \mathrm{M})$ of $\mathrm{NaCl}$ are of smaller magnitudes than in younger rats. These changes might relate to alterations in receptor membranes.

\section{Conclusions}

Anatomical studies of the taste system in old humans and other animals have addressed simply the question of whether taste buds are lost in old age. Recent investigations in rodents [Mistretta \& Baum, 1984], primates [Bradley, et al., 1984] and humans [Arvidson, 1979] report no decrease in taste bud number as a function of age. However, there are studies from the 1930s reporting a substantial decrease in taste buds in human circumvallate papillae [Arey, et al., 1935; Mochizuki, 1937], and in a later study a decrease in taste bud numbers in old mouse circumvallate papilla was observed [Conger \& Wells, 1969]. New studies of taste buds in human circumvallate and foliate papillae from fresh, disease-free, cadaver specimens would be particularly valuable in finally resolving the contradictions that exist in this literature.

It should be noted, though, that in early studies which reported taste bud loss, large numbers of taste buds were still observed in circumvallate papillae even in the oldest tongues. So an overall decline in taste sensation would not be predicted necessarily [Mistretta, 1984]. Similarly, neurophysiological experiments have not demonstrated large changes in peripheral nerve taste responses in the rat, but rather, smaller alterations in relative responses.

However, there have been no investigations of possible ultrastructural changes in taste bud cells or synapses, nor have there been recordings from single, peripheral, taste nerve fibers to learn if one particular class of fibers has altered response characteristics. Furthermore, there have been no studies of various taste relays in the central nervous system. Thus, future experiments might discover more substantial changes than those observed to date.

Those recent studies that have been made on the light microscopic structure of taste buds and the neurophysiology of the peripheral taste innervation in- dicate that the peripheral gustatory system is well-maintained structurally and functionally in old age.

\section{OLFACTION}

The olfactory receptor cells are bipolar neurons, with dendrites that bear several motile cilia lying in a layer of mucus covering the olfactory epithelium. The axons, which comprise the olfactory nerve, travel to the olfactory bulb, to terminate and synapse with second order cells in networks called glomeruli. Thus, olfactory receptor neurons contrast with taste receptor cells, which are modified epithelial cells that synapse with first order, taste nerve fibers.

In the early 1940s, Smith [1942] counted the number of intact glomeruli in the olfactory bulbs from 121 human cadavers free of intracranial disease. He observed an agerelated reduction in numbers of normal glomeruli and attributed the atrophy to loss of olfactory receptor neurons. However, Smith noted the large inter-individual variability at any age, remarking on the occasional, extensive atrophy of glomeruli in younger individuals. Therefore he cautioned that nasal disease might play an important role in determining atrophy of olfactory structures.

More extensive studies of the olfactory system have been made in old rats [Hinds \& McNelly, 1977, 1979, 1981]. In the most recent of these investigations, Charles River rats that had been maintained under barrier conditions to prevent infection and thus, nasal disease, were used [Hinds \& McNelly, 1981]. Rats aged 3-36 months were studied; median life span is about 27 months. Approximately $10 \%$ of these rats survive beyond 32 months.

Numbers of olfactory receptor neurons were counted in the epithelium overlying the nasal septum. The septum was chosen since the epithelium in this region is a rather flat, homogeneous sheet, representing about $20 \%$ of the total olfactory epithelium. The number of septal olfactory receptors increased from 3 to 18 months and then decreased (Figure 3 ). The decline was initially slow, but accelerated from 29 to 33 months. However, although numbers of receptors were much reduced at 33 compared to 18 months, they were equal to numbers in 6 month animals.

Furthermore, new olfactory receptors were still appearing at 33 months. Olfactory receptor neurons turn over and are replaced in adults mammals [Graziadei \& Graziadei, 1978], similar to the taste bud cells. The percentage of immature receptors in the septal epithelium remained constant for 18 to 33 months [Hinds \& McNelly, 1981]. Apparently, though, in older animals the receptor neurons degenerate faster than they are replaced, and therefore total numbers of receptors decreased.

The second order neurons in the olfactory bulb of this Charles River rat strain were examined also and a constant number of mitral cell bodies was observed as a function of age [Hinds \& McNelly, 1981]. However, size of mitral cell bodies initially increased up to about 27 months, and then decreased. The decrease in size occurred about $3 \frac{1 / 2}{2}$ months later than the decrease in number of septal receptor neurons. This temporal association sug- 


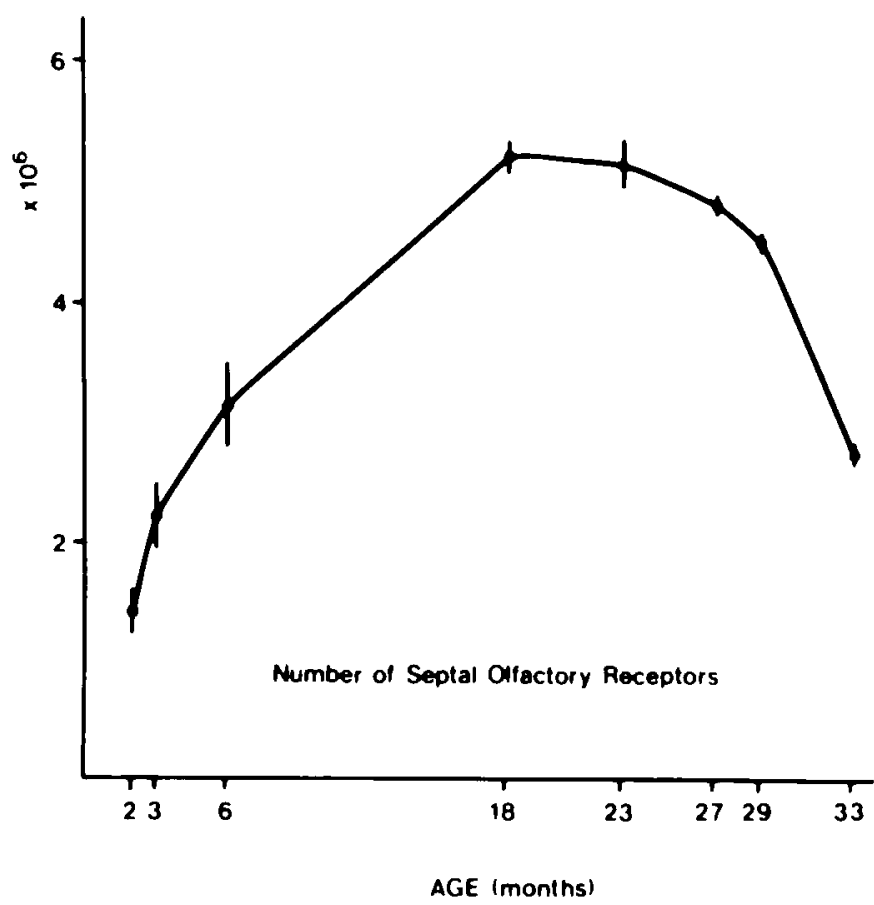

Figure 3. Number of olfactory receptors per right nasal septal epithelium in Charles River rats as a function of age. Data points are means and bars represent standard errors. This figure is taken from Hinds and McNelly [1981].

gests that the second order, mitral cells decrease in size due to a decrease in receptor cell input.

Interestingly, some compensatory mechanisms may occur in the olfactory bulb to offset the effects of receptor neuron loss. After 29 months, there is an increase in number of glomerular axodendritic synapses per receptor [Hinds \& McNelly, 1981]. Whether this would in fact relate to altered function is not known.

The general pattern of changes observed in the olfactory bulbs of Charles River rats was reported also in Sprague-Dawley Wisconsin rats [Hinds \& McNelly, 1977]. However, in the Sprague Dawley strain, loss of mitral cells was reported after 24 months whereas no loss was found in Charles River rats.

To learn whether vascular changes contribute to agerelated alterations in the olfactory bulbs of Charles River rats, capillaries in the bulb were studied with light and electron microscopy [Hinds \& McNelly, 1982]. There was no change with age in the mean diameter of capillaries nor was there a loss in capillary endothelial cells. There was an increase in thickness of the capillary basal lamina from 3 to 24 months; values plateaued beyond that. The biological significance of this is not understood.

\section{Conclusions}

Detailed investigations of olfactory receptor neurons and olfactory bulb structure have been made in rats through extreme old age. A general pattern of age-related changes in quantified parameters has emerged; there is usually an initial increase (e.g., in receptor number or second order cell size) followed by a slow decrease, and finally a more rapid decrease. It should be noted that the rapid decrease occurs between about 27 and 33 months, and as stated earlier, only about $10 \%$ of rats in the Charles River strain live to 33 months. So these animals are very old. Furthermore, the decline in various quantified parameters is usually to values equivalent to those at about six months [Hinds \& McNelly, 1981]. Presumably 6-month animals are not at risk for appropriate function.

Therefore, although there are substantial changes in the olfactory system in old rats, the biological significance of the changes cannot be assessed. Neurophysiological experiments to determine responses from the receptor epithelium and olfactory bulb in aged animals are necessary to establish possible functional deficits.

\section{GENERAL SUMMARY}

There are relatively few investigations of age-related differences in anatomy and neurophysiology of the chemical senses, taste and smell. In taste, the balance of recent observations indicates that there is no substantial loss of taste buds on the tongue in old animals or humans. One neurophysiological study suggests that functional deficits in the peripheral taste system of old rats are not large either. But there are no investigations of central taste pathways, and such studies could reveal alterations in aged animals that have the potential to affect feeding behavior.

In the olfactory system of old rats, an age-related difference in number of receptor neurons and in size of second order neurons has been demonstrated clearly. These parameters increase initially and then later decrease in old age. However, even in the oldest rats, the number of receptors equals that in animals aged six months. Therefore the possibility of functional deficits is ambiguous.

It might be that in the chemical senses, the reported observations on anatomy and neurophysiology do not match the extent of apparent perceptual alterations in the flavor of food that elderly individuals report. Confounding variables related to oral hygiene, medications, disease and social living conditions may well alter food appreciation in the elderly, and these should be examined carefully. In addition, more detailed, future studies of chemoreceptor structure and function could reveal new correlates of reported perceptual changes. Alternatively, since the taste and smell receptors turn over and are renewed throughout life, the chemical senses might be relatively resistant to age-related changes.

\section{REFERENCES}

Arey, L.B., Tremaine, M.J., \& Monzingo, F.L.: The numerical and topographical relations of taste buds to human circumvallate papillae throughout the life span. Anatomical Record, 64: 9-25, 1935.

Arvidson, K.: Location and variation in number of taste buds in human fungiform papillae. Journal of Dental Research, 87: 435-442, 1979.

Beidler, L.M., \& Smallman, R.L.: Renewal of cells within taste buds. Journal of Cell Biology, 27: 263-272, 1965.

Bradley, R.M.: Basic Oral Physiology. Chicago: Year Book 
Medical Publishers, 1981.

Bradley, R.M., Stedman, H.M., \& Mistretta, C.M.: A quantitative study of lingual taste buds and papillae in the aging rhesus monkey tongue. In R.T. Davis (Ed.), The Aging Rhesus Monkey. In press, 1984.

Brouwer, J.N., \& Wiersma, A.: Location of taste buds in intact taste papillae by a selective staining method. Histochemistry, 58: 145-151. 1978.

Cohen, A.M., \& Vig, P.S.: A serial growth study of the tongue and intermaxillary space. Angle Orthodontia, 46: 332-337, 1976.

Conger, A.D., \& Wells, M.A.: Radiation and aging effect on taste structure and function. Radiation Research, 37: 31-49, 1969.

Graziadei, P.P.C., \& Graziadei, G.A.M.: The olfactory system: A model for the study of neurogenesis and axon regeneration in mammals. In C. Cotman (Ed.), Neuronal Plasticity. New York: Raven Press, pp. 131-154, 1978.

Hinds, J.W., \& McNelly, N.A.: Aging of the rat olfactory bulb: Growth and atrophy of constituent layers and changes in size and number of mitral cells. Journal of Comparative Neurology, 171: 345-368, 1977.

Hinds, J.W., \& McNelly N.A.: Aging in the rat olfactory bulb: Quantitative changes in mitral cell organelles and somatodendritic synapses. Journal of Comparative Neurology, 184: 811-820, 1979.

Hinds, J.W., \& McNelly, N.A.: Aging in the rat olfactory system: Correlation of changes in the olfactory epithelium and olfactory bulb. Journal of Comparative Neurology, 203: 441-453, 1981 .
Hinds, J.W., \& McNelly, N.A.: Capillaries in aging rat olfactory bulb: a quantitative light and electron microscopic analysis. Neurobiology of Aging, 3: 197-207, 1982.

McBride, M.: Neurophysiology of the peripheral taste system in aged rats and implications for food intake in elderly humans. Doctoral dissertation, University of Michigan, Ann Arbor, 1983.

McBride, M., \& Mistretta, C.M.: Chorda tympani nerve responses to taste stimuli in young and aged rats. Association for Chemoreception Sciences. Abstract, Sarasota, Florida, 1983.

Mistretta, C.M.: Taste anatomy and neurophysiology in early development and old age. In H.L. Meiselman \& R.S. Rivlin (Eds.), Clinical Measurement of Taste and Smell. Massachusetts: Collamore Press, in press, 1984.

Mistretta, C.M., \& Baum, B.J.: Quantitative study of taste buds in fungiform and circumvallate papillae of young and aged rats. Journal of Anatomy, 138: 323-332, 1984.

Mochizuki, Y.: An observation on the numerical and topographical relations of taste buds to circumvallate papillae of Japanese. Okajimas Folia Anatomical Japonica, 15: 595-608, 1937.

Mochizuki, Y.: Studies on the papilla foliate of Japanese. 2. The number of taste buds. Okajimas Folia Anatomical Japonica, 18: 355-369, 1939.

Moses, S.W., Rotem, Y., Jagoda, N., Talmor, N., Eichhorn, F., \& Levin, S.: A clinical, genetic and biochemical study of familial dysautonomia in Israel. Israel Journal of Medical Science, 3: 358-371, 1967.

Smith, C.G.: Age incidence of an atrophy of olfactory nerves in man. Journal of Comparative Neurology, 77: 589-595, 1942. 
This document is a scanned copy of a printed document. No warranty is given about the accuracy of the copy. Users should refer to the original published version of the material. 